\title{
Incidência e Enquadramento: Uma Possibilidade de Transmissão da Prática Atoral
}

\section{Rejane Kasting Arruda}

Doutoranda

Formação do Artista Teatral - orientação Prof. Dr. Armando Sergio da Silva

Bolsista da FAPESP

Membro do Centro de Pesquisa em Experimentação Cênica do Ator (USP).

Resumo: Este texto apresenta uma revisão da pesquisa "O Ateliê do Ator-encenador". Verifica-se a hipótese do "vetor anteparo e impressão digital" (a relação entre material e ação física inscrita em cena) como estruturador da prática atoral. Investiga-se o princípio do arranjo (vários anteparos atuando juntos para a criação de uma impressão digital) e chega-se a funções mínimas articuladas (incidência, enquadramento e vulnerabilidade) para instrumentalizar a prática pedagógica. Conta-se com um procedimento inventado pela pesquisadora através da intersecção de diferentes pedagogias que o texto expõe, juntamente com o deslocamento epistemológico proposto (através de uma apropriação de termos do ensino lacaniano).

Palavras-chave: ator-encenador, criação cênica, pedagogia do teatro

Title: Incidence and Framing: A Possibility of transmission of the Actor's Practice

Abstract: This paper presents a review of the research "The Atelier of the Actor-director". It is hypothesized that the "vector shield and fingerprint" (the relationship between material and physical action inscribed on the scene) as structuring for the actor's practice. The principle of arrangement (multiple shields working together to create a fingerprint) is researched and it reaches minimum articulated functions (incidence, framing and vulnerability) in order to organize pedagogical practice. It is used a procedure invented by the researcher through the intersection of various pedagogies exposed by the text, along with the proposed epistemological shift (via an appropriation of terms from Lacanian guideline).

Keywords: actor-director, scenic creation, theater pedagogy

Título: Incidencia y Encuadramiento: Una Posibilidad de Transmisión de la Práctica Actoral

Resumen: Este texto presenta una revisión de la investigación "El Atelier del Actor-Director". Verificándose la hipótesis de los "vectores anteparo e impresión digital" (la relación entre material y acción física inscrita en la escena) como estructuradores de la práctica actoral. Se investiga el principio de "composición" (varios anteparos actuando juntos para la creación de una impresión digital) llegándose a funciones mínimas articuladas (incidencia, encuadramiento y vulnerabilidad) para instrumentalizar la práctica pedagógica. Se cuenta con un procedimiento inventado por la investigadora a través de la intersección de diferentes pedagogías que el texto expone, en conjunto con el dislocamiento epistemológico propuesto (a través de una apropiación de términos de la enseñanza lacaniana).

Palabras-clave: actor-director, creación escénica, pedagogía de teatro

Em 2011 publicamos, na revista "aSPAs", uma reflexão sobre a relação entre anteparo e impressão digital (Silva, 2010) - o material no jogo do ator e a ação física inscrita em cena resultante deste jogo - enfatizando a irredutibilidade desta última à leitura (ao efeito de significação) e propondo-a como "letra" (conceito extraído de Lacan). Se a cena, 
contemporaneamente, pode ser tomada como uma escritura, as impressões digitais seriam, então, as suas letras.

O conceito de letra nos permite situar um indizível (caro a contemporaneidade) sem, no entanto, deixar de apresentá-lo articulado ao jogo do significante e aos seus efeitos de significação. "A significação se produz para cada sujeito particular (...) abrindo margem para os jogos significantes, mais notadamente a polissemia. (...) A letra é então tomada como elemento idêntico a si mesmo que permite jogos de repetição e conservação" (AIRES, 2012: 14). A letra é tomada como o que resiste à significação enquanto o espectador joga com a interpretação através da escuta dos significantes (que a cena do corpo implica). Para além dos significantes que ele escuta (na leitura do corpo) ou para além dos efeitos de significação do discurso cênico - que dependem das relações entre estes significantes e cuja interpretação "convoca o desejo" (Soler, 2010). A letra, idêntica a si mesma, "em seu caráter material imutável" resiste (AIRES: idem).

No entanto, o modo operacional da inscrição da impressão digital em cena não tinha sido formalizado. Criamos, então, um procedimento para investigar funções implicadas no vetor que vai do anteparo (material em jogo) à impressão digital (inscrição do corpo em cena). Instruções de jogo e outras modalidades de imagens acústicas (utilizadas no processo de criação) - como a descrição do corpo, a fala interna, a nomeação dos movimentos e das imagens - foram tomadas como anteparos e registradas em um texto (escrito no papel): um "pré-jogo" (termo que propomos). Tal como na "Memorização Através da Escrita" de François Khan ${ }^{\mathrm{i}}$ (procedimento em que o ator repete a escrita de um texto-dado antes de falar em cena), a escrita deste pré-jogo foi repetida até a memorização. Esta repetição se estabeleceu como um "Treino na Imobilidade" (Grotowski)ii: um treino “dos impulsos" (e não da organização espaço-temporal do corpo).

O procedimento se configurou como uma estratégia para unir partitura e improvisação. No texto manuscrito o que está partiturizado são os anteparos (materiais) e não as impressões digitais (resultantes do jogo de improvisação com estes materiais). Em cena, atualiza-se a excitabilidade causada no exercício de repetição das nomeações (pela escrita). Ou seja, em cena atualiza-se a reverberação das incidências de toda uma cadeia de anteparos nomeados (cujas substituições implicam sucessivas renovações do impulso ${ }^{\text {iii }}$. A partir desta atualização, se experimenta variações do desenho corporal em cena, mantendo o princípio da improvisação, mesmo que a cadeia de anteparos esteja fixada. De maneira que se une o detalhamento (partiturização) com a improvisação (contingência, criação). 
A perspectiva de ser tomado corporalmente pelos ecos da incidência de uma subpartitura (Barba, 1995) - no caso, o pré-jogo - indica a possibilidade de manejo de uma área de vulnerabilidade. Nesta área (aberta entre a incidência de um material que situa o foco - no momento do jogo - e o enquadramento constituído) o ator improvisa. As reverberações da incidência do préjogo são atualizadas porque a memória corporal é vulnerável ao atravessamento do verbo. Cada falasser $^{\text {iv }}$ (Lacan) está sujeito à linguagem (a uma bateria de significantes). Mas também a um modo singular de gozo: um estilov . Para além da linguagem, há algo irredutível ao sentido, que não é passível de compartilhamento via linguagem ou identificado via imagem. Para além do que se captura na via do sentido, está a alingua ${ }^{v i}$ : "o puro jogo sonoro sem-sentido" (IANNINI, 2012: 264). Trata-se de um sem sentido situado no atrelamento do corpo ao verbo.

É neste ponto do ensino lacaniano que encontramos o fundamento para a repetição do préjogo pela escrita. O verbo implica a "água suja, obscena" da alingua (Soler, 2010) - que não entra na estrutura da linguagem, mas alojam-se neste lugar de gozo: o corpo. "Para além do princípio do prazer"vii, o gozo é excesso, sofrimento. A hipótese é que o ator, ao sofrer a incidência do verbo na repetição do pré-jogo, é convocado ao gozo, excesso, sofrimento, transbordamento, que funciona como uma espécie de "cola" na cadeia dos anteparos.

A repetição da escrita provoca o excesso de um "sofrer dos sons" (ou, ainda, de um "sofrer dos ritmos") implicados nos revezamentos dos materiais acústicos na cadeia - em um momento de intimidade sem, ainda, o enquadramento (organização espaço-temporal) em cena. No momento da escrita, o enquadramento é a imobilidade, o que implica uma resistência aos impulsos para as ações, potencializando-os. Em cena, aparece a plasticidade de um corpo tomado pela reverberação destes impulsos (transpassado, vulnerável). Em cena, as sucessivas trocas entre os anteparos do pré-jogo implicam sucessivas renovações do impulso e, ao mesmo tempo, o detalhamento da partitura resultante. No entanto, a memória corporal implica, para além desta cadeia planejada, a atualização contingente, que não se controlada; algo novo, um precipitado que aparece, estabiliza-se e pode ser repetido (tal como uma escrita, como uma sucessão de letras).

ARRANJO DE ANTEPAROS

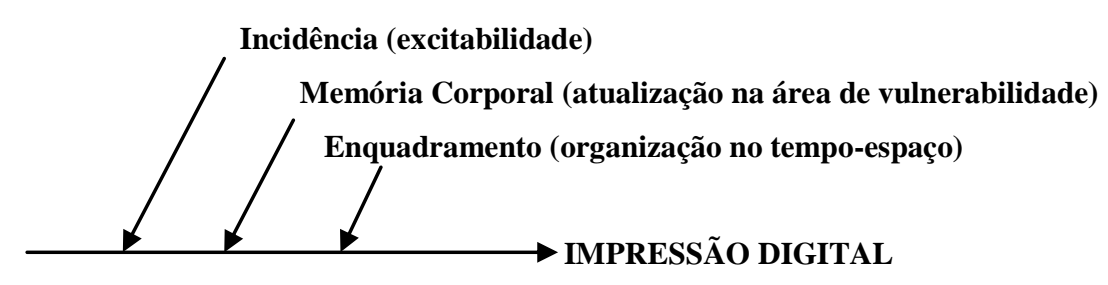


O termo anteparo é encontrado também em Merleau-Ponty com alusão explícita à função da proteção. Mas o anteparo protege do quê? Em Merleau-Ponty, trata-se de um pequeno objeto redondo colocado entre o olho e a luz. O anteparo protege da luz. Esta formalização implica a função do olhar, presente também na experiência cênica. Até que algo seja construído, é o olhar do espectador que incide no corpo. No "Jogo da Exposição" de Spolin (SPOLIN, 2001: A1) trata-se de manter-se sob a observação do espectador "sem fazer nada" durante um minuto. Trata-se de estar sem anteparos? Ou apenas sem aqueles que intencionalmente se coloca entre o corpo e o olhar? Materiais que aparecem em associações súbitas durante a cena (atravessando, invadindo o ator) seriam anteparos? Tomar o vetor anteparo - impressão digital como a instância estrutural da prática significa dizer que todo material isolável (que se define pela sua diferença e causa excitabilidade) é anteparo? Se for assim, quando o ator dá uma resposta à direção, esta é anteparo. Assim como uma imagem, uma fala interna (Kusnet, 1992) ou externa, uma instrução de jogo (Spolin, 2001), um som ou um movimento são anteparos - que atuam juntos.

Esta excitabilidade (que os anteparos causam no corpo e que implicam a impressão digital) nós chamamos de "incidência". O termo é encontrado em Lacan justamente em alusão à inscrição do significante no corpo. Ele vem a substituir "estímulo", termo disseminado na cultura teatral. Por quê? Porque não se trata da "relação estímulo e resposta" - tal como um estímulo ao órgão (que responde a um tratamento) ou a reação de fechar as pálpebras frente à ameaça de algo entrar nos olhos (como resposta a um estímulo). Na criação cênica não se sabe nada da resultante, que implica a contingência dos encontros nos arranjos e a reverberação em um corpo singular. Além disto, o termo incidência implica a noção de que um anteparo pode ser acachapado no corpo tal como a bola de basquete é acachapada na rede: em "um ponto" de incidência, de vulnerabilidade.

Em Lacan, um significante se articula em cadeias verticais de possíveis substituições, sem que necessariamente esteja inscrito no eixo horizontal (em uma sucessão, disposto no tempo): “ $E$ pelo fato dos significantes se embutirem, se comporem, se engavetarem (...) que se produz algo que, como significado, pode parecer enigmático” (IANNINI, 2012: 265 upud LACAN, 1985: 51). Há um eixo vertical na estrutura da linguagem que implica a "presença na ausência"viii. A hipótese do arranjo implica que anteparos funcionem tal como os significantes: empilhados no eixo vertical (cuja incidência banha o corpo). Assim, a impressão digital está sujeita às contingências dos encontros de anteparos que por sua vez implicam, entre si, uma relação de verticalidade. Assim, a impressão digital é a resultante sempre fresca de reverberações que transpassam a tessitura corporal 
e perdemos de vista (enquanto os anteparos funcionam como estes significantes cujas reverberações são atualizadas).

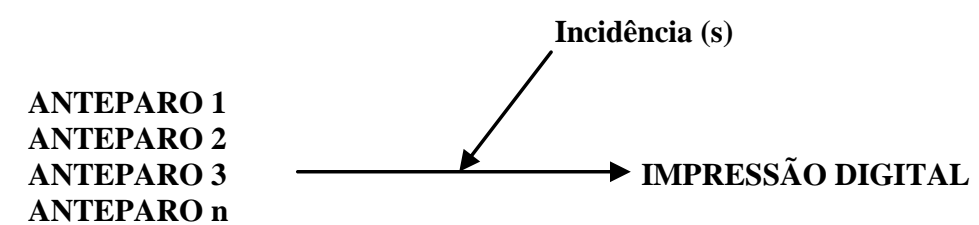

No entanto, a cena implica também o encadeamento; a disposição de materiais no eixo horizontal. O que cabe no olhar?

(...) eu penso no canto dos olhos, a mão tem um certo ritmo, vejo minha mão com meus olhos, do lado dos meus olhos quando falo minha mão faz um certo ritmo, procuro concentrar-me e não olhar para o grande movimento de leques (referência às pessoas se abanando no auditório) e num certo ponto olho para certos rostos, isto é uma ação" (Grotowski, 1998)

O foco desliza entre materiais que se substituem, como uma câmera de cinema recortando a superfície da cena. A hipótese do vetor anteparo-impressão digital como estruturador da prática se sustenta na medida em que estes materiais (isoláveis que o foco recorta) são tomados como anteparos. Parte da impressão digital está implicada no tempo-espaço cênico: esta parte cujos fragmentos o ator captura com o canto do olho graças à propriedade de diferenciar, de recortar, da linguagem. Esta parte se situa em uma ponta do foco. A outra parte da impressão digital se situa “fora do foco". Há algo que não se captura; que não é imagem; não se inscreve nos elementos diferenciais da linguagem. $\mathrm{O}$ foco é uma função da estrutura colada à impressão digital na medida em que algo dele escapa.

Quando Spolin introduz, em cena, com a sua voz, a instrução de jogo "conte as cadeiras do auditório", o ator consegue sustentar o seu corpo no tempo. A instrução conduz a uma organização temporal na medida em que se desdobra: "um, dois, três, quatro (cadeiras)". O enquadramento surge com a propriedade de organizar os efeitos das incidências, enquanto a memória corporal atualiza reverberações que fazem pressão sobre ele e tendem a deformá-lo. A impressão digital é resultante desta tensão. Com o enquadramento, o ator está protegido (vestido). Apesar da excitação, que brota do corpo, há materiais que o enquadram. O olhar do outro se volta para o enquadramento (é este que deve aparecer quando encontra sua razão de ser no olhar do outro). 


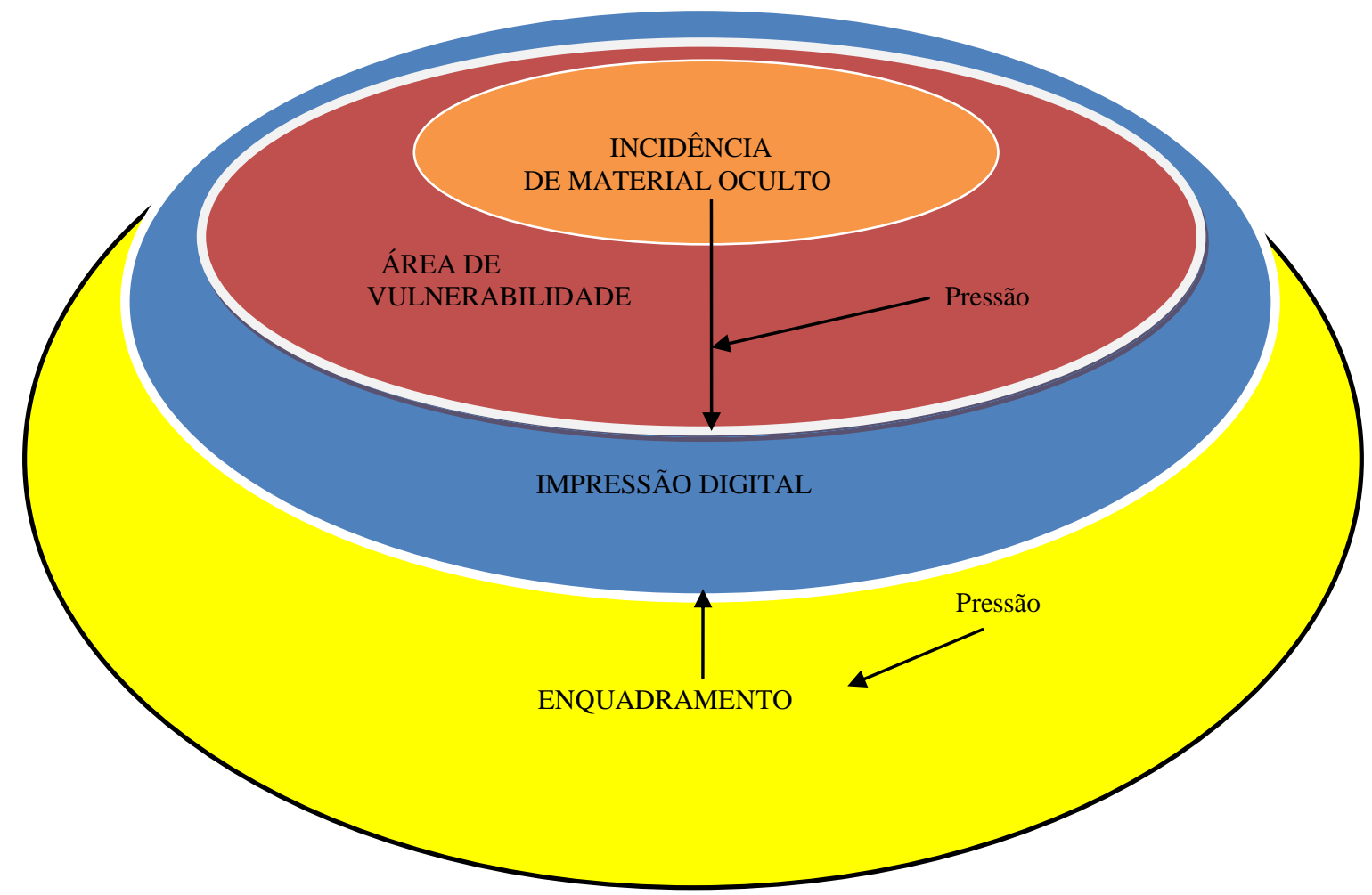

Mas existem modalidades diferentes de enquadramento. A produção atoral pode ser enquadrada, por exemplo, na ação inscrita em uma ficção (cuja plasticidade implica certos limites): a impressão digital é situada neste tempo-espaço outro que não o cênico que o espectador vê. $\mathrm{O}$ espectador põe em cena a plasticidade do seu olhar na medida em que esta também enquadra a produção do ator.

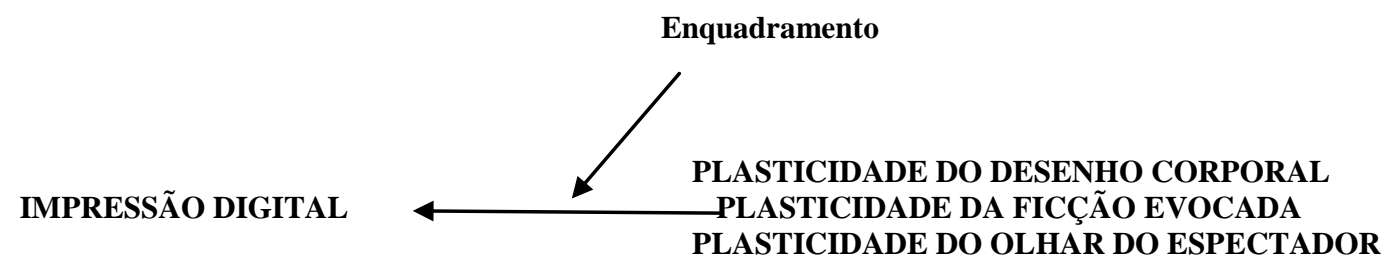

Em Silva, de que proteção se trata? Da proteção de um corpo que ainda não tem o estatuto de cênico; não possui o tratamento plástico que a inscrição na poética cênica, contemporaneamente ou historicamente, implica; um corpo banalizado, que não possui o estatuto de arte. Em Silva, a fala do texto dramático causa excitabilidade, implicando a identificação imediata com a ideia de ação e a imagem extraída do campo da realidade (com a plasticidade comum) para enquadrá-la. De maneira que o ator necessita do anteparo. Intencionalmente introduzido, este se apresenta como um caminho para a construção de uma poética corporal: "Pintores, fotógrafos, eles desenham melhor o corpo no 
espaço. Uma cabeça da Tarsila: pode ajudar você a fazer um pescoço longo em cena... Pode servir para você desenhar o corpo" (Silva, 2012) ${ }^{\mathrm{ix}}$ A plasticidade do material é inscrita na poética visual do corpo. Uma poética do desenho (ou uma poética do estranho) oposta ao que é comum (ao corpo inscrito na plasticidade do seu cotidiano). Mas há os anteparos de enquadramento e também aqueles que não enquadram (eles apenas incidem). Esta constatação, testemunhada pela prática, implica a função do arranjo: um anteparo enquadra no tempo, outro no espaço enquanto as reverberações de um quarto, quinto ou sexto, são atualizadas sem que o ator se dê conta.

ARRANJO DE ANTEPAROS

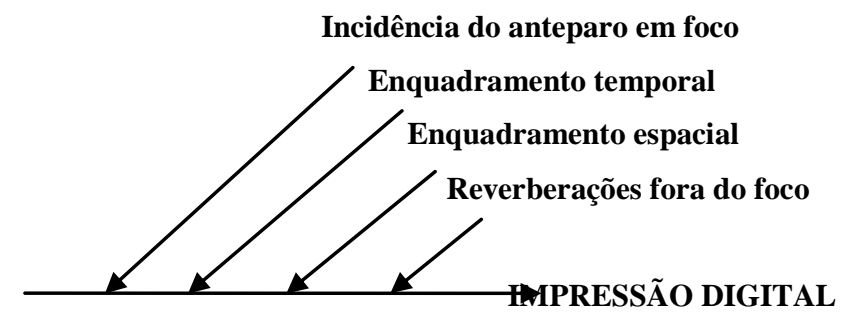

O trabalho com o anteparo que Silva chama "iconográfico" (a imagem extraída da obra de um pintor) deixa transparecer a função do enquadramento espacial. No entanto, outras modalidades, como a música, não a implicam. O desenho do corpo está livre para ser criado com a incidência do som na medida em que algo fora do foco é atualizado. Estão em jogo as reverberações de materiais que suportam o desenho corporal. Neste caso, o arranjo conta com ecos impressos na memória que, fora do foco, atualizam o enquadramento.
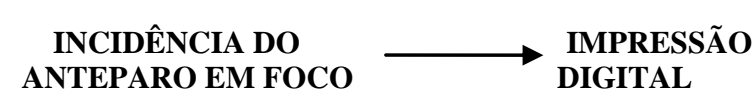

ATUALIZAÇÃO (FORA DO FOCO) DA MEMÓRIA CORPORAL (ENQUADRAMENTO)

\section{Conclusão:}

Partimos da hipótese do vetor anteparo-impressão digital como estruturador da prática e investigamos (através de um ateliê de encenação e da interface proposta), funções nele implicadas. Extraímos uma estrutura que pode se desdobrar em alguns princípios de trabalho. A estrutura formalizada funciona como uma espécie de convocação à prática, uma espécie de programa de pesquisa, a partir do qual podemos colocar questões e engendrar, a cada criação, um modo singular de usar o que aqui produzimos. Trata-se de operar a prática em diferentes ateliês com estes conceitos, experimentando modalidades de enquadramento diferentes e maneiras diferentes de manejar a área de vulnerabilidade. A singularidade que escapa à concepção racional é vislumbrada 
como horizonte: um resto da operação, algo que cai do corpo e se fixa na cena, letra inventada, que convoca o espectador (no desejo de interpretá-la) a colocar algo de si.

\section{Bibliografia}

AIRES, Suely. Da Quase Equivalência a Necessidade de Distinção: Significante e Letra na Obra de Lacan. Psicanálise e Filosofia: Discussão Teórica e Clínica, 2012. Disponível em: http://www.psicanaliseefilosofia.com.br/textos.html

ARRUDA, Rejane Kasting. Subpartitura e Texto-dado: A Troca para a Inscrição do Impulso. Anais da V Reunião Científica da ABRACE, São Paulo, ECA/USP, 2009b.

BARBA, Eugenio. A Canoa de Papel: Tratado de Antropologia Teatral. São Paulo: Hucitec, 1995.

BONFITTO, Matteu. O Ator-compositor: As Ações como Eixo: de Stanislavski a Barba. São Paulo: Perspectiva, 2007.

GROTOWSKI, Jerzy. Sobre o Método das Ações Físicas. Palestra no Festival de Teatro de Santo Arcangelo (Itália), 1988. Disponível em: http://www.grupotempo.com.br/tex_grot.html

IANNINI, Gilson. Estilo e Verdade em Jacques Lacan. São Paulo: Autêntica, 2012.

KHAN, François. Reflexões sobre a Prática da Memória no Ofício do Ator de Teatro. Revista Sala Preta, ECA/USP, v. 9, 2009.

KUSNET, Eugenio. Ator e Método. São Paulo: Hucitec, 1992.

SILVA, Armando (org). CEPECA, Uma Oficina de PesquisAtores. São Paulo: Associação dos Amigos da Praça, 2010.

SOLER, Collete. O “corpo falante”. In: FINGERMANN, Dominique. (org.) Caderno de Stylus, n.1. Rio de Janeiro: Internacional dos Fóruns do Campo Lacaniano, 2010.

SPOLIN, Viola. O Fichário de Viola Spolin. São Paulo: Perspectiva, 2001.

\footnotetext{
${ }^{\mathrm{i}}$ Ver em KHAN, F. Reflexões sobre a Prática da Memória no Ofício do Ator de Teatro. Revista Sala Preta, ECA/USP, v. 9, 2009.

ii "Sem que os outros percebam, pode-se treinar as ações físicas, e fazer as composições das ações físicas permanecendo no nível dos impulsos. Isso que dizer que as ações ainda não aparecem mas estão no corpo, porque são im/pulso. (...) É somente assim que se pode treinar as ações físicas. Mas há mais; as vossas ações físicas serão assimiladas ainda mais pela vossa natureza se treinarem os impulsos, não as ações. Podemos dizer que a ação física quase nasceu, mas ainda é bloqueada, e assim, no nosso dizer, estamos "impostando" uma reação justa, assim como se imposta a voz" (BONFITTO, 2007: 74 upud RICHARDS, 1993: 94).

iii Trabalhamos a troca como inscrição do impulso em ARRUDA, R. K. Subpartitura e Texto-dado: A Troca para a Inscrição do Impulso. Anais da V Reunião Científica da ABRACE, São Paulo, ECA/USP, 2009b.

iv Neologismo criado por Lacan.

v Em Lacan o estilo aparece como uma modalidade de formalização do singular impossível de dizer.

vi Conceito desenvolvido por Lacan (em francês lalangue).

vii $\mathrm{O}$ princípio do prazer implica uma tendência à satisfação, que Freud opõe ao "princípio de realidade", que, por sua vez abre caminho para a formulação da pulsão de morte, retomada por Lacan em função da ideia de gozo.

viii Lacan dialogou com Sausurre, que propôs a formalização da língua com dois eixos: horizontal e vertical.

ix Fala extraída de debate no CEPECA em 15/03/2012.
} 